\title{
Bevacizumab Trough Concentration in Recurrent Glioblastoma Patients
}

\section{Tabouret $\mathrm{E}^{1,2 *}$, Rousseau $\mathrm{B}^{3,4}$, Barrié $\mathbf{M}^{1}$, Bequet $\mathrm{C}^{1}$, Thiebault $\mathrm{L}^{3}$, Chinot $\mathbf{O}^{1,2}$ and Hulin $\mathrm{A}^{5}$}

${ }^{1}$ Assistance Publique des Hopitaux de Marseille, Timone Hospital, Department of Neuro-Oncology, 13005, Marseille, France

${ }^{2}$ Aix-Marseille Univ, CRO2, UMR911, 13005, Marseille, France

${ }^{3}$ Assistance Publique Hopitaux de Paris, Medical Oncology, Clinical Pharmacology, Henri Mondor Teaching Hospital, 94010 Creteil, France

${ }^{4}$ Paris Est Creteil University, UMR955, Team 18, 94010 Creteil, France

${ }^{5}$ Assistance Publique Hopitaux de Paris, Biological Pharmacology laboratory, Henri Mondor Teaching Hospital, 94010 Creteil, France

\begin{abstract}
Purpose: Predictive marker of bevacizumab activity is an unmet medical need. Our objective was to evaluate the trough concentration of bevacizumab in patients with recurrent glioblastoma and to analyze its potential association with patient characteristics and outcome.

Methods: We retrospectively included patients with recurrent glioblastoma treated with bevacizumab and chemotherapy with available plasma collected before the second bevacizumab administration (residual time). Trough bevacizumab concentrations and antibodies against bevacizumab were quantified by enzyme linked immunosorbent assay (ELISA).

Results: We included 21 patients with a median age of 63.4 years at bevacizumab initiation. Occurrence of antibody against bevacizumab was not observed. Median pre-cycle 2 trough concentration of bevacizumab was 87.1 $\mu \mathrm{g} / \mathrm{mL}$ (range, $21.7 \mu \mathrm{g} / \mathrm{mL}-151.8 \mu \mathrm{g} / \mathrm{mL}$ ). Trough concentration of bevacizumab was not correlated to patient age $(p=.529)$, gender $(p=.622)$, weight $(p=.403)$, size $(p=.871)$, Body Mass Index $(p=.439)$, Karnofsky Performans Status $(p=.988)$ and steroid intake $(p=0.403)$. No correlation was found between trough bevacizumab concentration and response rate $(p=.856)$. The highest tertile of trough bevacizumab concentration tended to be associated with poor progression-free survival $(p=0.152)$, while no correlation was observed for overall survival.
\end{abstract}

Conclusion: Evaluation of the trough concentration of bevacizumab during treatment for patients with glioblastoma is feasible and highly variable. Its prognostic value should be explored in prospective trial.

Keywords: Bevacizumab; Glioma; Trough concentration; Antibody

\section{Introduction}

Glioblastoma remains the most frequent and aggressive primary brain tumor for adult. This tumor was characterized by an extensive angiogenesis and a high VEGFA expression [1]. Recently, bevacizumab, a monoclonal antibody against VEGFA, was associated with a valuable but heterogeneous activity for patients with recurrent high grade glioma [2,3]. In addition to standard of care for newly glioblastoma, the use of bevacizumab in first line was associated with a prolonged progression-free (PFS) and maintenance of functional independence but no difference was observed for overall survival (OS) $[4,5]$. Given this heterogeneous activity and the uncertain impact on OS, a predictive biomarker of bevacizumab activity remains an unmeet medical need. To date, in contrast with other targeted therapy such as anti-EGFR, no biomarker has been validated for bevacizumab despite numerous studies. As a consequence, a large number of patients are exposed to bevacizumab with a possible unfavorable risk/ benefit balance. With the use of cetuximab, a monoclonal antibody directed against EGFR in patients with metastatic colo-rectal cancer, a retrospective study suggested that cetuximab trough concentration could be associated with progression-free survival [6]. Considering bevacizumab, pharmacokinetics is known to be highly variable from one patient to another and its clearance has been correlated to gender, weight, tumor burden, albumin, and inflammation [7]. Moreover, the inter-patient variability of bevacizumab for glioblastoma patients is unknown because most of the available data came from clinical trials excluding brain tumors.

Our objective was to evaluate the pre-cycle 2 trough concentration of bevacizumab in patients with recurrent glioblastoma and to test its potential association with patient characteristics and outcome.

\section{Methods}

We retrospectively included all adult patients referred to our institution for recurrent glioblastoma who received bevacizumab at the dose of $15 \mathrm{mg} / \mathrm{kg}$ every 3 weeks, with or without associated chemotherapy (alkylating agent: CCNU or BCNU) with available plasma samples (Assistance Publique-Hôpitaux de Marseille Tumor Bank, authorization number 2013-1786) at the time of the second bevacizumab administration (first residual sample). Clinical and imaging evaluations were performed every 3 weeks and 6 weeks respectively. Responses were reviewed using the RANO criteria [8].

Plasma bevacizumab concentration was quantified by enzyme linked immunosorbent assay (Elisa, Theradiag, Croissy Beaubourg, France) [9]. This method uses biotinylated recombinant human VEGF conjugated to an anti-Human IgG ( $\gamma$-chain specific), $F\left(a^{\prime}\right.$ ')2 fragmentPeroxidase antibody and absorbance was measured at $450 \mathrm{~nm}$. The lower and upper limits of quantification were 2.5 and $300 \mathrm{mg} / \mathrm{L}$ respectively. Interday precision was below $15 \%$.

Antibodies against bevacizumab were determined using the same principle (Theradiag kit).

*Corresponding author: Emeline Tabouret, Service de Neuro-Oncologie, CHU Timone, 265 rue Saint Pierre, 13385, Marseille Cedex 5, France, Tel: +33491385500; E-mail: tabouret@gmail.com

Received July 01, 2015; Accepted July 15, 2015; Published July 22, 2015

Citation: Tabouret E, Rousseau B, Barrié M, Bequet C, Thiebault L, et al. (2015) Bevacizumab Trough Concentration in Recurrent Glioblastoma Patients. J Integr Oncol 4: 138. doi:10.4172/2329-6771.1000138

Copyright: ( 2015 Tabouret E, et al. This is an open-access article distributed under the terms of the Creative Commons Attribution License, which permits unrestricted use, distribution, and reproduction in any medium, provided the original author and source are credited. 
Citation: Tabouret E, Rousseau B, Barrié M, Bequet C, Thiebault L, et al. (2015) Bevacizumab Trough Concentration in Recurrent Glioblastoma Patients. J Integr Oncol 4: 138. doi:10.4172/2329-6771.1000138

Page 2 of 3

Correlation between bevacizumab pre-cycle 2 trough concentrations and patient characteristics were analyzed using the Spearman correlation and the Mann Whitney U tests. Survival analyses were performed using the Kaplan Meier and the Log Rank tests.

\section{Results}

We included 21 patients with a median age of 63.4 years at bevacizumab initiation (Table 1). Majority of patients receiving chemotherapy in association with bevacizumab: CCNU $(\mathrm{N}=13)$ or $\mathrm{BCNU}(\mathrm{N}=5)$. Occurrence of antibody against bevacizumab was not observed in our cohort. Median pre-cycle 2 trough concentration of bevacizumab was $87.1 \mu \mathrm{g} / \mathrm{mL}$ (range, $21.7 \mu \mathrm{g} / \mathrm{mL}-151.8 \mu \mathrm{g} / \mathrm{mL}$ ). Trough concentration of bevacizumab does not appear to be correlated to patient age $(\mathrm{p}=.529)$, gender $(\mathrm{p}=.622)$, weight $(\mathrm{p}=.403)$, size $(\mathrm{p}=.871)$, Body Mass Index $(\mathrm{p}=.439)$, Karnofsky Performans Status $(\mathrm{p}=.988)$ and steroid intake $(p=0.403)$ at the time of bevacizumab initiation. No correlation was found between trough bevacizumab concentration and response rate $(\mathrm{p}=.856)$. Survival impact of bevacizumab concentration was then analyzed after dichotomization of the trough concentration by the median; subsequently, we compared the highest tertile versus the two lowest tertiles of concentration. No correlation was found between the trough bevacizumab concentration and the overall survival of patients. However, the highest tertile of trough concentration tended to be associated with poor progression-free survival $(\mathrm{p}=0.152)$ (Figure 1).

\section{Discussion}

Despite several retrospective researches on potential biomarkers that may predict bevacizumab efficacy, no robust biomarker has emerged to date, and the identification of a predictive marker of bevacizumab efficacy remains an unmeet medical need. Several circulating or tissue biomarkers were explored but the results remained limited and never confirmed [10]. The aim of our study was to explore the potential impact of the pre-cycle 2 trough concentration of bevacizumab on patient outcome. Analysis of trough concentration after bevacizumab administration is feasible for glioblastoma patients and this trough concentration presented large inter-patient variations (from 21.7-151.8 $\mu \mathrm{g} / \mathrm{mL}$ ), which does not appear to be correlated to patients characteristics. These concentrations were in line with those previously reported for other solid tumors [7]. We explored the potential prognostic value of this trough concentration

\begin{tabular}{|c|c|c|}
\hline Factors & $\mathrm{N}$ & $\%$ \\
\hline Median age (years) & \multicolumn{2}{|c|}{$63,9(42,5-89,8)$} \\
\hline Median BMI (m²) & \multicolumn{2}{|c|}{$1,85(1,5-2,0)$} \\
\hline Median weight (kg) & \multicolumn{2}{|c|}{$72,0(52-98)$} \\
\hline Median size $(\mathrm{cm})$ & \multicolumn{2}{|c|}{$171(155-196)$} \\
\hline Gender (Men/Women) & $15 / 6$ & $71,4 / 28,6$ \\
\hline \multicolumn{3}{|l|}{ KPS } \\
\hline 60 & 6 & 28,6 \\
\hline 70 & 9 & 42,8 \\
\hline $80-90$ & 6 & 28,6 \\
\hline \multicolumn{3}{|l|}{ Treatment } \\
\hline $\mathrm{Bev}+\mathrm{CCNU}$ & 13 & 61,9 \\
\hline $\mathrm{Bev}+\mathrm{BCNU}$ & 5 & 23,8 \\
\hline Bev. Alone & 3 & 14,3 \\
\hline Steroid (median, range) & \multicolumn{2}{|c|}{$40(0-80)$} \\
\hline \multicolumn{3}{|l|}{ Response } \\
\hline Complet response & 1 & 5 \\
\hline Partial response & 6 & 28 \\
\hline Stable disease & 5 & 24 \\
\hline Progression & 9 & 43 \\
\hline
\end{tabular}

Table 1: Patient characteristics.

and observed a trend between the highest trough concentrations and a poor progression-free survival. Of note, we evaluated the trough concentration of free circulating bevacizumab which does not take account of the bevacizumab bound to the VEGFA. A higher trough plasma concentration of bevacizumab could be assimilated to a lower chelation of the VEGFA by the bevacizumab, or could suggest a higher diffusion into cerebral. In animal models, it has been shown that lower plasma exposition of rituximab was correlated with a higher diffusion in tumor [11]. The prognostic value of trough concentration and these hypotheses should be obviously explored in larger and prospective trials using repeated measurements of bevacizumab.

Our study presented limitations: it is a retrospective study with a very limited number of patients and some pharmacokinetics parameters were absent of our data record. However, it is the first study exploring the feasibility and the potential prognostic impact of the trough concentration of bevacizumab for neuro-oncological patients in a homogenous cohort of recurrent glioblastoma.
A

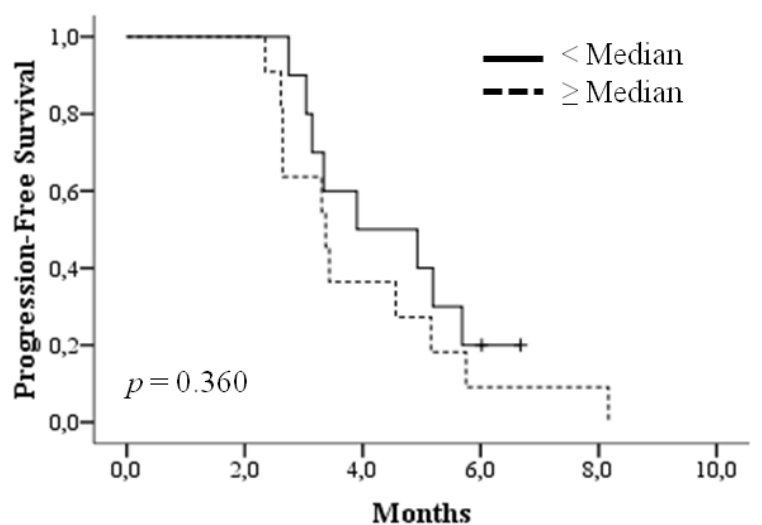

$\mathrm{B}$

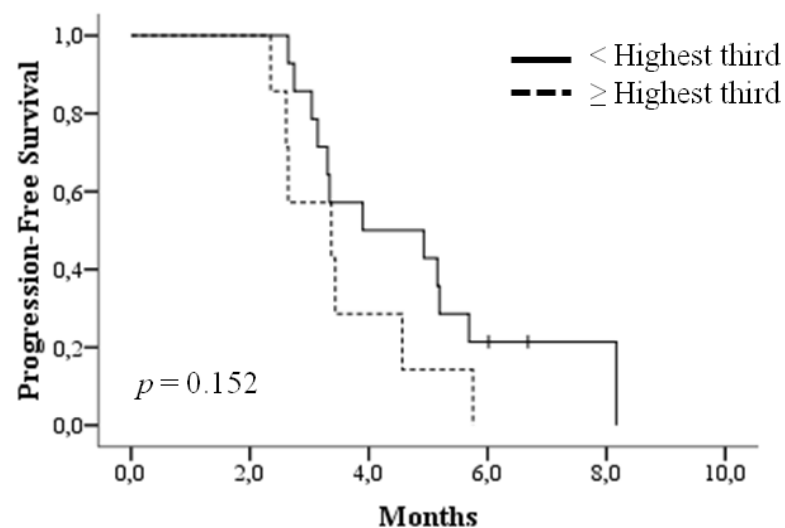

Figure 1: Progression-free survival of patients according the trough concentration of bevacizumab, segregated by the median concentration (A) or by the highest third concentration $(B)$. 
Citation: Tabouret E, Rousseau B, Barrié M, Bequet C, Thiebault L, et al. (2015) Bevacizumab Trough Concentration in Recurrent Glioblastoma Patients. J Integr Oncol 4: 138. doi:10.4172/2329-6771.1000138

Evaluation of the trough concentration of bevacizumab for patients with glioblastoma is feasible and highly variable. Prognostic value of this dosage should be explored in prospective trial.

\section{Acknowledgments} 6038

This work was completed in the SIRIC of Marseille, grant INCa-DGOS-Inserm

\section{References}

1. Plate KH, Breier G, Weich HA, Risau W (1992) Vascular endothelial growth factor is a potential tumour angiogenesis factor in human gliomas in vivo. Nature 359: 845-848

2. Friedman HS, Prados MD, Wen PY, Mikkelsen T, Schiff D, et al. (2009) Bevacizumab alone and in combination with irinotecan in recurrent glioblastoma. J Clin Oncol 27: 4733-4740.

3. Kreisl TN, Kim L, Moore K, Duic P, Royce C, et al. (2009) Phase II trial of single-agent bevacizumab followed by bevacizumab plus irinotecan at tumor progression in recurrent glioblastoma. J Clin Oncol 27: 740-745.

4. Chinot OL, Wick W, Mason W, Henriksson R, Saran F, et al. (2014) Bevacizumab plus radiotherapy-temozolomide for newly diagnosed glioblastoma. $\mathrm{N}$ Engl J Med 370: 709-722.
5. 5.Gilbert MR, Dignam JJ, Armstrong TS, Wefel SJ, Blumenthal DT, et al. (2014) A randomized trial of bevacizumab for newly diagnosed glioblastoma. $\mathrm{N}$ Eng J Med 370: 699-708.

6. Azzopardi N, Lecomte T, Ternant D, Boisdron-Celle M, Piller F, et al. (2011) Cetuximab pharmacokinetics influences progression-free survival of metastatic colorectal cancer patients. Clin Cancer Res 17: 6329-6337.

7. Lu J-F, Bruno R, Eppler S, Novotny W, Lum B, et al. (2008) Clinical pharmacokinetics of bevacizumab in patients with solid tumors. Cancer Chemother Pharmacol 62: 779-786.

8. Wen PY, Macdonald DR, Reardon DA, Cloughesy TF, Sorensen AG, et al (2010) Updated response assessment criteria for high-grade gliomas: response assessment in neuro-oncology working group. J Clin Oncol 28: 1963-1972.

9. Ternant D, Cézé N, Lecomte T, Degenne D, Duveau AC, et al. (2010) An enzyme-linked immunosorbent assay to study bevacizumab pharmacokinetics. Ther Drug Monit 32: 647-652.

10. Jubb AM, Harris AL (2010) Biomarkers to predict the clinical efficacy of bevacizumab in cancer. Lancet Oncol 11: 1172-1183.

11. Daydé D, Ternant D, Ohresser M, Lerondel S, Pesnel S, et al. (2009) Tumor burden influences exposure and response to rituximab: pharmacokineticpharmacodynamic modeling using a syngeneic bioluminescent murine mode expressing human CD20. Blood 113: 3765-3772. 